\title{
Combining SERVQUAL and QFD to Evaluate and Improve Airline Service Quality
}

\author{
Jeffrey E. Jarrett ${ }^{1}$, Xia Pan ${ }^{2}$, Yi Yang ${ }^{3}$, Youyou Huang ${ }^{3}$, Lingyan Huang ${ }^{3} \&$ Fenglin $\mathrm{Li}^{3}$ \\ ${ }^{1}$ University of Rhode Island, USA \\ ${ }^{2}$ Clark University, USA \\ ${ }^{3}$ Macau University of Science and Technology, Macau, China \\ Correspondence: Xia Pan, Clark University, USA. E-mail: panpapers@yahoo.com
}

Received: December 17, 2018

Accepted: February 13, 2019

Online Published: April 18, 2019

doi:10.5539/ijbm.v14n5p154

URL: https://doi.org/10.5539/ijbm.v14n5p154

\begin{abstract}
Purpose: This paper shows how to evaluate and analyze the service quality for airline business and provide feasible suggestions to improve the service. The purpose is to illustrate how the two quality improvement methods, SERVQUAL and QFD, can be combined and used to improve the service quality for service companies such as airlines.
\end{abstract}

Design/Methodology/Approach: The data were obtained by the way of interviewing the customers who have experienced the service offered by Air Macau, with tool of SERVQUAL. Comparing the perceived scores of Air Macau to the customers' expected value as well as to its competitors, we finally believe that the shortest board of service quality is the "responsiveness" among its five dimensions. Quality function deployment is then used to translate customers' actual requirements into practical service measures to further improvement.

Findings: It is more effective if SERVQUAL is combined with QFD in evaluating firm's quality and quality improvement.

Research Limitations: Effectiveness should be tested over time with bottom line evidences.

Practical Implications: Practitioners should use more than one effective methods in quality improvement whenever possible.

Social Implications: People are more aware of SERVQUAL and QFD.

Keywords: service quality, SERVQUAL, quality function deployment, quality improvement, quality management, combined methods

\section{Introduction}

Tourism industry played an important and dominant role in Macau's economic development. Visitors' experiencing the service industry is the overall impression of the entire Macau fundament. And aviation industry has a direct impact on the quality of service upon international visitors' first impression to Macau. As the local's largest airline company and as the first line to face tens of thousands of international tourists, quality of service of Air Macau represent the overall Macau aviation industry service quality.

To study and probe Air Macau service real problems and bottleneck, this paper utilizes data to make statistics analysis via the use of SERVQUAL and QFD house of quality as well as data derived from questionnaire survey. Thus we can make an assessment of Air Macau, to find out the gap between results customers perceived and ideal value in their minds. Meanwhile we make comparisons with China Southern Airlines, domestic airline company to figure out weaknesses of Macau Airline.

Compare to famous international airlines, quality of service has become one of the obstacles that slow the upgrade of competitiveness. Complaints from the network analysis illustrate that service quality is the problem customers concentrated, mainly related to poor service attitude, flight delays and so on. But how to measure the level of service? Where are the specific problems? How is the feeling of customer perceived? What are customers' expectations? Which problems are the bottlenecks?...... To draw the appropriate answer, we need to use standard evaluation tools SERVQUAL quality questionnaires and QFD layer. Followed we will select data 
via standard SERVQUAL questionnaire survey of customer perceptions and expectations, then take advantage of QFD for quality statistical analysis to come to our survey results and conclusions. Our approach, integrating different available methods in the application is consistent to the concept that quality management should be viewed in way of cybernetics, proposed by Pan (2006).

\section{SERVQUAL}

\subsection{Introduction to SERVQUAL Model}

In 1988, American sales training experts Parasuraman, Zeithamal and Berry proposed the famous service quality assessment method - SERVQUAL model (short for service quality), which obtained many marketing scientists' approvals and was considered to be a typical method that was suitable in evaluating each kind of service quality.

In SERVQUAL model, customers' perceptions decide the customers' appraisals, and customers' perceptions of service quality depend on the difference between customer's perception of what customers expect and what they actually receive. (Therefore this model also is called "expectation-perception" model). The perception of service quality is a comprehensive judgment or view about whether the service has high quality. Service perception is the feeling what customers actually experience. Customer's perception is decided by organization' each activity including superintendent's management, staff's service and so on. Customer's expectation is that customer's demand and desire, for instance they think the service provider should provide some kinds of service for them, but not will provide. It is based on organization's market communication, organization's image, other customer's oral propaganda, and customers' needs/wants and so on. Customer's expectation is precondition in development high-quality. The key to provide high-quality service is to surpass the user's expectation.

SERVQUAL model: SERVQUAL score $=$ actual feeling score - expectation score.

\subsection{Using SERVQUAL Model for Evaluating Service Quality of Air Macau}

SERVQUAL is an empirically derived method that may be used by a service organization to improve service quality. The resulting gap analysis may be used as a driver for service quality improvement. SERVQUAL is an assessment model that assesses service quality from the standpoint of customers, depends on whether meet customers' needs, and draws attention on service ideas that keeping the centered on customers in the process. SERVQUAL can bring valuable diagnostic message to enterprises, be easy to use, and its cost is low. The SERVQUAL model has demonstrated the enormous superiority in evaluating service quality.

This method will compare with some outstanding company which is professional in some service and industry. Finally, to analysis the gap between performances the enterprise really showed and what customers expected, which will help enterprises improve their service quality. We will use SERVQUAL model to appraise AIR Macau's service quality, collect the grades of what customers expect of a service and what they actually receive in Air Macau using standardized questionnaire, find the disparity between what customers expect and what the Air Macau actually delivery. At the same time, we take the well- known Chinese airline — China Southern Airline as comparison object, contrast the disparity between Air Macau and China Southern Airline, and finally seek for the insufficiency.

\subsection{Questionnaire Survey}

\subsubsection{Questionnaire Design}

There are 5 factors: tangibles, reliability, responsiveness, assurance, and empathy, also called five key dimensions.

TANGIBLES - the appearance of physical facilities, equipment, personnel and information material.

RELIABILITY - the ability to perform the service accurately and dependably. RESPONSIVENESS - the willingness to help customers and provide a prompt service. ASSURANCE - a combination of the following: Competence - having the requisite skills and knowledge; Courtesy - politeness, respect, consideration and friendliness of contact staff; Credibility - trustworthiness, believability and honesty of staff. Security - freedom from danger, risk or doubt.

EMPATHY - a combination of the following: Access (physical and social) - approachability and ease of contact; Communication - keeping customers informed in a language they understand and really listening to them; Understanding the customer - making the effort to get to know customers and their specific needs

The SERVQUAL survey has two parts; (1) customer expectations and (2) customer perceptions. In the questionnaire, the customers" expectation is defined as "what the service should do". Grading takes 7 values, "7" 
means strongly agree, while " 1 " means strongly disagree, the others are "very agree" "agree" "general" "disagree" "very disagree", the values decrease progressively in turn. First, we should measure the customers" expectations, which are made up of past experience, advertisement, promotion, enterprise image and word-of-mouth and so on; then to measure customers' perceptions, what they actually receive in Air Macau and China Southern Airline.

\subsubsection{Questionnaire Collection}

We carried out 90 sampling investigations (Air Macau 30 copies, China Southern Airline 30 copies, Air Macau\& China Southern Airline 30 copies), take back 90 copies. Effective questionnaire rate is $100 \%$

Table 1. Statistical result of our questionnaire collection

\begin{tabular}{|c|c|c|c|c|}
\hline 1.Gender & M 41 & F 49 & & \\
\hline 2.How many times & 1-2times:38 & 3-5times:20 & Above 5 tiems: 32 & \\
\hline 3.Education & bachelor: 82 & master: 6 & high school: 2 & \\
\hline 4.Reasons & Business Trip: 8 & Visiting Relatives:17 & Travelling:43 & Others:26 (school, inexpensive) \\
\hline
\end{tabular}

\subsubsection{Test for the Equality of Three or More Population Means}

Because we choose different target participants to fulfill the questionnaire, we need an ANOVA to test whether the expectation values of different region people are significantly different. According to the 22 different questions listed on SERVQUAL, we need to do ANOVA test for each question to test whether the average is significantly different under different sample.

We first construct a hypothesis test as follows:

$\mathrm{H}_{0}: \mu_{1}=\mu_{2}=\mu_{3} \quad$ (Null)

$\mathrm{H}_{\mathrm{a}}$ : Not all population means are equal (Alternative)

ANOVA table for Question1:

\begin{tabular}{lllll}
\hline Source & Sum of Squares & degree of freedom & Mean Square & F value (MSTR/MSE) \\
\hline Regression & 2.16 & 2 & 1.08 & 1.07 \\
Error & 87.40 & 87 & 1.00 & \\
Total & 89.56 & 89 & & \\
\hline
\end{tabular}

Here we know that the numerator degree of freedom $\left(\delta_{1}\right)$ is equal to $3-1=2$ and the denominator degree of freedom $\left(\delta_{2}\right)$ is equal to $90-3=87$, and let's suppose $\alpha=0.05$. Checking the $F$ distribution table, we fail to find the exact value when $\delta_{1}=2$ and

$\delta_{2}=87$, but we find two adjacent value to estimate it. We find that when $\delta_{1}=2$, and $\delta_{2}=60$, the critical value $=3.15$, and when $\delta_{1}=2$, and $\delta_{2}=120$, critical value $=3.07$, so we can conclude that the critical value under the condition $\delta_{1}=2$, and $\delta_{2}=87$, should between 3.15 and 3.07. Because the $F$ value $=1.07<\mathrm{F}_{0.05}(2,87)$, we conclude that the expectation value from different regions are not significantly different.

Using the same method, we produce the Analysis of Variance (ANOVA) for the remaining 21 questions, and the results are shown below:

ANOVA table for Question2:

\begin{tabular}{lllll}
\hline Source & Sum of Squares & degree of freedom & Mean Square & F value (MSTR/MSE) \\
\hline Regression & 0.47 & 2 & 0.23 & 0.17 \\
Error & 117.63 & 87 & 1.35 & \\
Total & 118.1 & 89 & & \\
\hline
\end{tabular}


ANOVA table for Question3:

\begin{tabular}{lllll}
\hline Source & Sum of Squares & degree of freedom & Mean Square & F value (MSTR/MSE) \\
\hline Regression & 0.47 & 2 & 0.23 & 0.33 \\
Error & 61.93 & 87 & 0.71 & \\
Total & 62.4 & 89 & & \\
\hline
\end{tabular}

ANOVA table for Question4:

\begin{tabular}{lllll}
\hline Source & Sum of Squares & degree of freedom & Mean Square & F value (MSTR/MSE) \\
\hline Regression & 2.49 & 2 & 1.24 & 1.67 \\
Error & 64.67 & 87 & 0.74 & \\
Total & 67.16 & 89 & & \\
\hline
\end{tabular}

ANOVA table for Question5:

\begin{tabular}{lllll}
\hline Source & Sum of Squares & degree of freedom & Mean Square & F value (MSTR/MSE) \\
\hline Regression & 0.96 & 2 & 0.48 & 0.68 \\
Error & 61.53 & 87 & 0.71 & \\
Total & 62.49 & 89 & & \\
\hline
\end{tabular}

ANOVA table for Question6:

\begin{tabular}{lllll}
\hline Source & Sum of Squares & degree of freedom & Mean Square & F value (MSTR/MSE) \\
\hline Regression & 2.16 & 2 & 1.08 & 1.73 \\
Error & 54.33 & 87 & 0.62 & \\
Total & 56.49 & 89 & & \\
\hline
\end{tabular}

ANOVA table for Question7:

\begin{tabular}{lllll}
\hline Source & Sum of Squares & degree of freedom & Mean Square & F value (MSTR/MSE) \\
\hline Regression & 0.87 & 2 & 0.43 & 0.45 \\
Error & 83.63 & 87 & 0.96 & \\
Total & 84.5 & 89 & & \\
\hline
\end{tabular}

ANOVA table for Question8:

\begin{tabular}{lllll}
\hline Source & Sum of Squares & degree of freedom & Mean Square & F value (MSTR/MSE) \\
\hline Regression & 1.36 & 2 & 0.68 & 0.57 \\
Error & 104.3 & 87 & 1.2 & \\
Total & 105.66 & 89 & & \\
\hline
\end{tabular}

ANOVA table for Question9:

\begin{tabular}{lllll}
\hline Source & Sum of Squares & degree of freedom & Mean Square & F value (MSTR/MSE) \\
\hline Regression & 0.87 & 2 & 0.43 & 0.48 \\
Error & 78.73 & 87 & 0.9 & \\
Total & 79.6 & 89 & & \\
\hline
\end{tabular}

ANOVA table for Question10:

\begin{tabular}{lllll}
\hline Source & Sum of Squares & degree of freedom & Mean Square & F value (MSTR/MSE) \\
\hline Regression & 1.27 & 2 & 0.63 & 0.59 \\
Error & 93.63 & 87 & 1.08 & \\
Total & 94.9 & 89 & & \\
\hline
\end{tabular}


ANOVA table for Question11:

\begin{tabular}{lllll}
\hline Source & Sum of Squares & degree of freedom & Mean Square & F value (MSTR/MSE) \\
\hline Regression & 0.87 & 2 & 0.43 & 0.55 \\
Error & 68.73 & 87 & 0.79 & \\
Total & 69.6 & 89 & & \\
\hline
\end{tabular}

ANOVA table for Question12:

\begin{tabular}{lllll}
\hline Source & Sum of Squares & degree of freedom & Mean Square & F value (MSTR/MSE) \\
\hline Regression & 1.76 & 2 & 0.88 & 0.85 \\
Error & 89.90 & 87 & 1.03 & \\
Total & 91.66 & 89 & & \\
\hline
\end{tabular}

ANOVA table for Question13:

\begin{tabular}{lllll}
\hline Source & Sum of Squares & degree of freedom & Mean Square & F value (MSTR/MSE) \\
\hline Regression & 3.82 & 2 & 1.91 & 2.02 \\
Error & 83.23 & 87 & 0.95 & \\
Total & 87.05 & 89 & & \\
\hline
\end{tabular}

ANOVA table for Question14:

\begin{tabular}{lllll}
\hline Source & Sum of Squares & degree of freedom & Mean Square & F value (MSTR/MSE) \\
\hline Regression & 0.69 & 2 & 0.34 & 0.34 \\
Error & 88.43 & 87 & 1.02 & \\
Total & 89.12 & 89 & & \\
\hline
\end{tabular}

ANOVA table for Question15:

\begin{tabular}{lllll}
\hline Source & Sum of Squares & degree of freedom & Mean Square & F value (MSTR/MSE) \\
\hline Regression & 1.42 & 2 & 0.71 & 0.74 \\
Error & 83.20 & 87 & 0.96 & \\
Total & 84.62 & 89 & & \\
\hline
\end{tabular}

ANOVA table for Question16:

\begin{tabular}{lllll}
\hline Source & Sum of Squares & degree of freedom & Mean Square & F value (MSTR/MSE) \\
\hline Regression & 2.22 & 2 & 1.11 & 2.01 \\
Error & 48.10 & 87 & 0.55 & \\
Total & 50.32 & 89 & & \\
\hline
\end{tabular}

ANOVA table for Question17:

\begin{tabular}{lllll}
\hline Source & Sum of Squares & degree of freedom & Mean Square & F value (MSTR/MSE) \\
\hline Regression & 1.87 & 2 & 0.93 & 0.94 \\
Error & 86.23 & 87 & 0.99 & \\
Total & 88.1 & 89 & & \\
\hline
\end{tabular}

ANOVA table for Question18:

\begin{tabular}{lllll}
\hline Source & Sum of Squares & degree of freedom & Mean Square & F value (MSTR/MSE) \\
\hline Regression & 0.42 & 2 & 0.21 & 0.18 \\
Error & 102.7 & 87 & 1.18 & \\
Total & 103.12 & 89 & & \\
\hline
\end{tabular}


ANOVA table for Question19:

\begin{tabular}{lllll}
\hline Source & Sum of Squares & degree of freedom & Mean Square & F value (MSTR/MSE) \\
\hline Regression & 1.09 & 2 & 0.54 & 0.45 \\
Error & 106.20 & 87 & 1.22 & \\
Total & 107.29 & 89 & & \\
\hline
\end{tabular}

ANOVA table for Question20:

\begin{tabular}{lllll}
\hline Source & Sum of Squares & degree of freedom & Mean Square & F value (MSTR/MSE) \\
\hline Regression & 1.76 & 2 & 0.88 & 0.54 \\
Error & 140.47 & 87 & 1.61 & \\
Total & 142.23 & 89 & & \\
\hline
\end{tabular}

ANOVA table for Question21:

\begin{tabular}{lllll}
\hline Source & Sum of Squares & degree of freedom & Mean Square & F value (MSTR/MSE) \\
\hline Regression & 1.27 & 2 & 0.63 & 0.39 \\
Error & 141.23 & 87 & 1.62 & \\
Total & 142.5 & 89 & & \\
\hline
\end{tabular}

ANOVA table for Question22:

\begin{tabular}{lllll}
\hline Source & Sum of Squares & degree of freedom & Mean Square & F value (MSTR/MSE) \\
\hline Regression & 0.27 & 2 & 0.13 & 0.08 \\
Error & 143.33 & 87 & 1.65 & \\
Total & 143.6 & 89 & & \\
\hline
\end{tabular}

To summarize, we find that the maximum of the $\mathrm{F}$ values for 22 questions is 2 , but the critical value is between 3.07 and 3.15, which means that $F$ values are absolutely less than the critical value. So our conclusion of the 22 questions is that the expectation values of the questionnaires from 3 different regions are not significantly different, therefore, the meaningful goal is to gather all the data together regardless of its source region.

2.3.4 Analysis of Questionnaire Results

\subsubsection{Framework of the Study}

At first, to find the difference between customers' expectations of service and the service that customers actually receive in Air Macau. At the same time, to calculate the difference customers' expectation and what customers actually receive in China Southern Airline. Second, we compared the Air Macau's results with China Southern Airline's results. Finally, seek for the disparity and make the improvement.

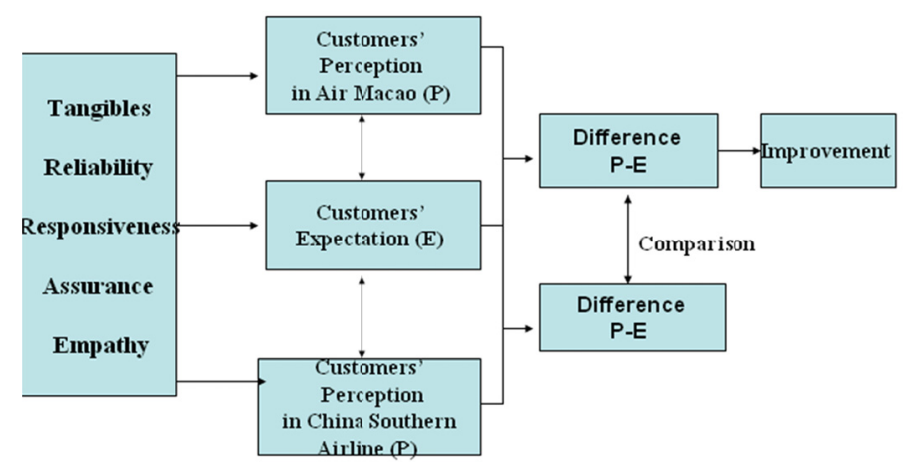

\section{Research Approach}

Research variable:

1. Customers' perception (P). Customers' perception is that the degree that customers actually receive the service which Airlines delivery.

2. Customers' expectation (E). Customers' expectation is the "satisfied service" which customers think that ideal 
Airlines should delivery.

3. Difference (P-E). It is the difference between what customers expect of a service and what they actually receive. According to the positive or negative and size of P-E value, we may judge the Airlines' service quality. When P-E is positive, it means the service what customers actually receive is better than that the customers expect. This Airline's service quality tends to perfect; when P-E is negative, it means the service what the Airline deliveries doesn't meet the customers' needs. This Airline should improve their service quality. When P-E is around zero, it means that this company has provided the service which just meets the customers' needs. We will seek for specific reasons that why company's service quality cannot meet customers' needs, according to assess 22 differences in expectations and perceptions by using the differencing technique. Finally, we should improve and enhance the service quality.

We have calculated 22 means of customers' expectation on the basis of the 90 questionnaires, average expectation of 60 questionnaires of Air Macau and 60 questionnaires of China Southern Airline, and SERVQUAL 5 dimensions. As follows:

Table 2. SERVQUAL Analysis of 90 questionnaires

\begin{tabular}{llllll}
\hline Item & Air & Macau China & Southern & Air Average & Air Macau Difference \\
number & Ave. Perception & Ave. Perception & Expectation & & southern \\
Difference & \\
\hline 1 & 5.20 & 5.17 & 6.22 & -1.02 & -1.05 \\
2 & 4.72 & 4.97 & 5.77 & -1.05 & -0.80 \\
3 & 5.60 & 5.50 & 6.49 & -0.89 & -0.99 \\
4 & 5.00 & 5.10 & 6.38 & -1.38 & -1.28 \\
5 & 4.90 & 5.20 & 6.49 & -1.59 & -1.29 \\
6 & 4.80 & 5.27 & 6.49 & -1.69 & -1.22 \\
7 & 4.69 & 5.08 & 6.17 & -1.48 & -1.09 \\
8 & 4.69 & 5.07 & 6.32 & -1.63 & -1.25 \\
9 & 4.80 & 5.07 & 6.27 & -1.47 & -1.20 \\
10 & 4.90 & 5.14 & 6.30 & -1.40 & -1.16 \\
11 & 4.90 & 5.22 & 6.40 & -1.50 & -1.18 \\
12 & 5.20 & 5.15 & 6.32 & -1.12 & -1.17 \\
13 & 4.97 & 4.88 & 6.28 & -1.31 & -1.40 \\
14 & 4.95 & 5.22 & 6.15 & -1.20 & -0.93 \\
15 & 4.95 & 5.17 & 6.24 & -1.29 & -1.07 \\
16 & 5.42 & 5.40 & 6.54 & -1.12 & -1.14 \\
17 & 5.05 & 5.12 & 6.10 & -1.05 & -0.98 \\
18 & 4.87 & 4.95 & 6.14 & -1.27 & -1.19 \\
19 & 4.50 & 4.72 & 5.93 & -1.43 & -1.21 \\
20 & 4.34 & 4.75 & 5.56 & -1.22 & -0.81 \\
21 & 4.37 & 4.62 & 5.83 & -1.46 & -1.21 \\
22 & 4.15 & 4.80 & 5.73 & -1.58 & -0.93 \\
\hline
\end{tabular}

The averages for each of the dimensions of service quality were computed by averaging the items pertaining to the dimension. Finally, differences for the dimension were computed as follows:

Table 3. Summary of service quality for the five dimensions

\begin{tabular}{llllll}
\hline & Air Macau Perception & China Southern Air Perception & Expectation & Air Macau & China Southern Air \\
\hline Tangible Difference $=$ & 5.13 & 5.18 & 6.21 & -1.08 & -1.03 \\
Reliability Difference $=$ & 4.77 & 5.14 & 6.35 & -1.58 & -1.21 \\
Responsiveness Difference $=$ & 4.99 & 5.10 & 6.33 & -1.34 & -1.23 \\
Assurance Difference $=$ & 5.09 & 5.23 & 6.26 & -1.17 & -1.03 \\
Empathy Difference $=$ & 4.45 & 4.77 & 5.84 & -1.39 \\
\hline
\end{tabular}




\subsection{Analysis the service quality of Air Macau}

The differences show that the negative mismatches exist in five dimensions. In other words, the service quality that Air Macau delivered didn't meet customers' expectation. The dimension of reliability has greatest negative mismatch, with empathy as a close second. 22 items of P-E are all negative. We should improve the service quality of Air Macau. Among these, the score of difference in Air Macau "when a customer has a problem, excellent Airlines companies will show a sincere interest in solving it" is lowest. The score of "excellent Airline companies will have modern-looking equipment" is largest.

Therefore, the process improvement efforts should focus on improving reliability, the training program should also focus on teaching employees to be empathetic.

Table 2 shows, in five dimensions, Reliability difference >Empathy difference $>$ Responsiveness difference $>$ Assurance difference $>$ Tangible difference.

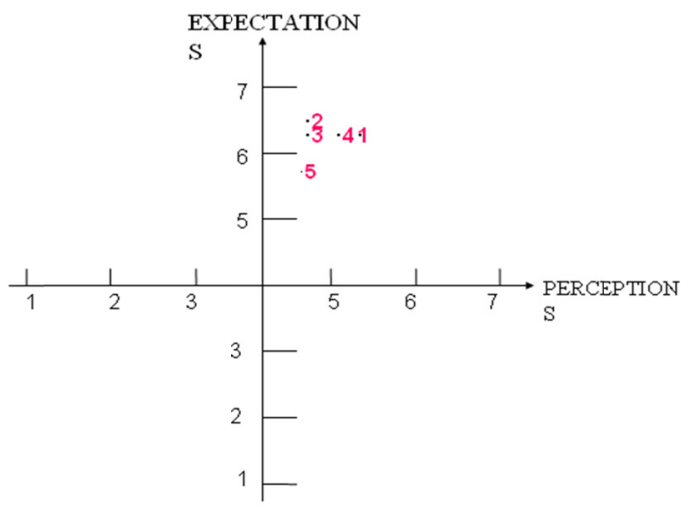

Figure 2. Two-dimensional services plane for Air Macau service quality

Note. 1. Tangible, 2. Reliability, 3. Responsiveness, 4. Assurance, 5. Empathy

Using the information form Table 2, it is fairly simple to develop a two-dimensional services plane. The vertical axis reflects the expectations score axis the horizontal axis relates to the perceptions score. We can learn that the areas of five dimensions where expectations are high and perceptions are all relatively low. The score of reliability difference is the lowest, so the Air Macau should improve this area at first.

\subsection{In comparison with China Southern Airline}

From the information of table 2-3, we can learn that the scores of differences in 5 dimensions of China Southern Airline are all larger than that of Air Macau. In others words, the service quality that China Southern Airline deliveries is better than the service quality that customers actually receive from Air Macau. Among the 22 questions, "1. Excellent airline companies will have modern- looking equipment" "3. Employees at excellent airline companies will be neat-appearing" "12. Employees in excellent airline companies will always be willing to help customers" "16. Employees in excellent airline companies will be consistently courteous with customers", the average perceptions of Air Macau are larger than that of China Southern Airline. The service quality what Air Macau deliveries in these 4 items receives customers' praise. The other 18 scores of Air Macau are all lower than that of China Southern Airline. So we could promote and improve the service quality of Air Macau, using China Southern Airline as standard reference.

\section{The QFD Analysis}

\subsection{QFD Model}

\subsubsection{Overview}

As discussed above, the definition of quality has changed radically, which is, from "meet the standard of design" to "satisfy the customer needs". It's actually a revolution for both manufacture and service industry.

Against such a backdrop, QFD (Quality Function Deployment) was first developed in Japan in the late 1960s by Professor Yoji Akan and Professor Shigeru Mizuno as a quality system. Basically, QFD developed from the method of fishbone. In 1972, with the application of QFD to the design of an oil tanker at the Kobe Shipyards of Mitsubishi Heavy Industry, the fishbone diagrams grew unwieldy. Since the effects shared multiple causes, the fishbone could be changed into a spreadsheet or matrix format. The rows were desired effects of customer 
satisfaction, and the columns were the controlling and measurable causes.

In 1978, the two professors integrated the QFD model in the book "Quality Function Deployment". Then QFD was introduced into America and adopted in the system of aircraft communication industry which achieved a great success. Following that, the U.S. Department of Defense issued DODD5000.51, the document of "Total Quality Management", in which the QFD was stated as the method of making military products. At the same time, QFD was absorbed by a lot of other industries in America such as Auto Industry and American Supplier Institute (ASI). It was used as one of the technical methods to decrease the fluctuation of quality and increase the reliability of products.

\subsubsection{Definition}

As described by Dr. Yoji Akan, QFD is a "method to transform user demands into design quality, to deploy the functions forming quality, and to deploy methods for achieving the design quality into subsystems and component parts, and ultimately to specific elements of the manufacturing process".

In short, QFD is a structured approach to defining customer needs or requirements (Voice of the Customer) and translating them into specific plans (Technical Requirement) to produce high quality products to meet those needs.

In detail, the "voice of the customer" is the term to describe these stated and unstated customer needs or requirements. We can capture those needs in a variety of ways, such as direct discussion or interviews, surveys, customer specifications, etc. This understanding of the customer needs is then summarized in a product planning matrix or "House of Quality". These matrices are used to translate higher level "what's" or needs into lower level "how's" - product requirements or technical characteristics to satisfy these needs. In addition, we always need the integration of each department, say, engineering, manufacturing, finance, and others, to ensure the process of improvement is efficient and effective. Only through a great cooperation in-house, we can get high quality products or services that satisfy the customers' needs indeed.

\subsubsection{Assumptions}

There are two basic assumptions for QFD: one is the market survey results are accurate. The other one states that customer needs can be documented and captured and they remain stable during the whole process.

The foundation of QFD method that we will use in the discussion of improving the service level of Air Macau are the conclusion of SERVQUAL questionnaire and the ANOVA analysis we have probed in section 2 . The 5 dimensions of SERVQUAL define and measure the actual need of customers. Indeed, the quantized needs are very useful for our further discussion of QFD.

\subsubsection{House of Quality}

The House of Quality is a sort of conceptual map, which provides means to the inter-functional planning and coordination of product improvement and product development. In a way this method brings the customer needs in the focus to design or to redesign the product and service. The customer actual needs which we got from the search form the base of the house. Corresponding engineering characteristics are specified which should be in clear measurable term. The interdependencies are mapped which are in the form of the roof of the house. Accordingly, technical difficulties in achieving the desired changes are calculated. Then the final targets are set in clear measurable terms. In essence with the help of customer needs, the product's design and redesign are realizable.

The House of Quality contains six major components: (1) Customer requirements: A structured list of requirements derived from customer statement. (2) Technical requirement: A structured set of relevant and measurable product characteristics. (3) Planning matrix: Illustrates customer perceptions observed in the market surveys. The matrix includes relative importance of customer requirements, company and competitor's performance in satisfying these requirements. (4) Interrelationship matrix: Illustrates the QFD team's perceptions of interrelationships between technical and customer requirements. (5) Technical correlation (Roof) matrix: Used to identify where technical requirements support or impede each other in the product design. By doing this, QFD teams can highlight innovation opportunities. (6) Technical priorities, benchmarks and targets: It's a matrix to record the priorities assigned to technical requirements, the measures of technical performance achieved by company and competitor, and the degree of difficulty involved in developing each requirement.

Figure 3 shows how the House of Quality structured. Now we will use such a model to discuss the detail steps for developing the service level of Air Macau. 


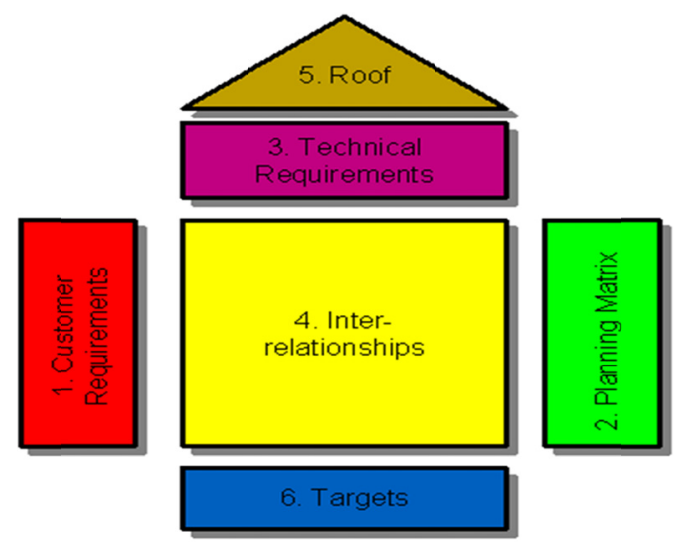

Figure 3. Structure of House of Quality

\subsection{Service improvement of Air Macau by using QFD}

\subsubsection{Capture Voice of the Customer}

Identifying the character and the content of service is a good starting of capturing the Voice of the Customer. It's important to remember that there is no one monolithic voice of the customer. Customer voices are diverse. All we need is the identified basic customer needs. Frequently, customers will try to express their needs in terms of "how" the need can be satisfied and not in terms of "what" the need is. The condition limits, or say, make it difficult to set the list of customer needs. So after capturing the responds from the customers, breaking down the general needs into more specific and defined requirements is essential.

As analyzed in Section 2, we captured the customer needs by using SERVQUAL questionnaire. Those needs were well defined and quantized during the design phase of questionnaire. Accordingly, the customer needs we stated are adaptive. According to the standardized questionnaire, the customer needs are defined as five dimensions: tangibles, reliability, responsiveness, assurance and empathy. Base on the SERVQUAL conclusion, "reliability" was the one we should put most attention to. Basically, it's under our preconception that "reliability" turned into the result: for the quality of air service, the meaning of reliability which include safe and punctual is the basic need of customers and the reason for choosing such a transportation method. Hence, we include reliability in the process evaluation.

The SERVQUAL identifies reliability as follows: (1) When excellent air company promises to do something by a certain time, they will do so. (2) When a passenger has a problem; excellent air company will show a sincere interest in solving it. (3) Excellent airline company will get things right the first time. (4) Excellent Airline Company will provide their services at the time they promise to do so. (5) Excellent Airline Company will insist on error-free records.

According to the output, for expectation, the first and second one issues got the highest score. That means the fulfilling of the promises and the solicitude shown are the most important factors to the passengers. Air Macau states promise of "To achieve the highest standards of safety and reliability" and "To deliver quality customer services". After considering the reality to Air Macau, we used a brainstorming method to get the segment of customer requirements. Table 3 shows all the 14 elements:

Table 3. All the 14 elements

\begin{tabular}{ll}
\hline Customer requirements (What) \\
\hline High standard of safe & Convenient to change flight \\
Low fault rate & Rational flight schedule \\
Little noise & Wide destination \\
Stable and comfortable & More flight frequency \\
Delicious food provided & High punctuality \\
& High efficiency \\
Variety language service & of solving problems \\
More promotions & Error-free record \\
\hline
\end{tabular}




\subsubsection{Build the "House of Quality"}

Since the customer requirements have been identified, the House of Quality can begin subsequently. The sequence of designing the air service improvement planning matrix is as follows:

1. The Voice of the Customer, which we shown in table 3, was listed in the left hand side of the matrix.

2. Establish the technical characteristics to respond to customer requirements and organize into related categories. In the case, we tried to find the specific technical characteristics and relative support technical requirements for air service. When we search the appropriate technical requirements, the 3 conditions have been considered: 1) Meaningful - must be subsequently actionable to drive the design process; they can't be abstract. 2) Measurable - must be able to define a garget value and clearly determine whether the characteristic has been achieved or not. 3) Global - must not imply or constrain design alternatives to any one technical solution or approach.

Obviously, the technical requirements of service are very different from those of manufacturing. Air service, particularly, has some features:

1) Intangible and abstract: the services provided by air transportation are intangible and various in kinds. Passengers cannot take a look nor have a try before pay. Also, it's hard to change or return purchase if the services "have defects" like a product.

2) Unsteady: affected by the weather, manual operation, machine condition and the structure of plane, the flight would not be as stable as we want. Although it's definitely safer than any other transportation mode, there would be very low survival rate and cause a huge death toll once an accident takes place.

3) It cannot be stored: once the air service provided, it should be consumed. For instance, it's a loss in condition that any ticket has not been purchased.

After discussing a few times, our team stated some relevant technical requirements and shown in Table 4:

Table 4. Relevant technical requirements

\begin{tabular}{ll}
\hline Technical requirements (How) & \\
\hline Type of aircraft & Storage of food \\
Materials and facilities & Design of flight \\
Flying experience of pilot & Staff Training \\
$\begin{array}{l}\text { Safety management system } \\
\text { Airbus line }\end{array}$ & Network support \\
operations monitoring system & Financial support \\
Storage of lash-up & Strategic alliance with \\
& other airline companies \\
\hline
\end{tabular}

3. Develop relationships between customer requirements and technical requirements. These relationships define the degree to which as technical characteristics satisfy the customer requirements. We used a set of symbols to mark them and also weights (we recommend using 9-3-1 weighting factors) to indicate the strength of the relationship - strong, medium and weak. As shown in the House of Quality, the relationships between passenger requirements and the aircraft technical requirements were defined in the middle of the House of Quality. Take customer requirements of "High standard of safe" as an example, we hold that it has "strong" relationship with the technical requirements of "Type of aircraft", "Materials and facilities", "Flying experience of pilot", "Safety management system"; "medium" relationship with "Airbus line operations monitoring system" and "weak" relationship with "Storage of lash-up". And it has scarcely any relationship with other technical requirements.

4. Demonstrate the correlations between technical requirements in the roof of the house. The same as forming the relationship between customer requirements and technical requirements, we used a series of symbols to mark the interrelationship of technical requirements. If improving one of the technical requirement help another one's improvement, we define they have positive correlation. On the contrary, it would be a negative correlation. In the process of evaluating the improvement planning, the engineer should take those technical requirements which have negative correlation into consideration firstly to eliminate or reduce bad effect. In the case, we used to mark the "strong positive relationship", $\bigcirc$ to mark the "positive relationship", $\times$ to mark the "negative 
relationship" and * to mark the "strong negative relationship". Accordingly, we gave the weights of each kind of relationship which are $+9,+3,-3$ and -9 .

5. Perform a competitive assessment of the customer requirements. It's an assessment of how the company product or service compares with those of the key competitors. In our case, we chose China South Airlines and Singapore Airlines as the competitors. This part illustrates the competitive landscape in the airline market. We can find out both the strengths and weakness of Air Macau in fulfilling the customer requirements. The comparisons are on a five-point scale with 5 being high. Shown on the right side of Figure3-2, "Us" stands for Air Macau, "A" means China South Airlines and "B" stands for Singapore Airlines. There are some reasons for choosing these two airline companies as the major competitors. First, all the three airline companies are located in Asia. Their culture is more or less similar with each other. Second, as the biggest airline company in Mainland China, the operation style and the achievement of China South Airlines is typical. Equally, Singapore Airlines has got very high evaluation from passengers all over the world. We believe it should be the quality benchmark in the airline market. Final, the quantized judge of opinion we got in the SERVQUAL questionnaire are the basis of assigning marks in this part.

6. Prioritize customer requirements. On the far right side of Figure3-2 are customer requirements priorities. These priorities include importance to customer, target value, sales point, and absolute weight.

Importance is a subjective assessment of how critical a particular customer requirement. It's on a 10-point scale, with 10 being most importance. The customer requirements which got relatively high score of importance and in low competitive assessments should be paid more attention to. According to the result of the questionnaire, we scored every customer requirement. For example, in the respect of "Convenient to change flight", the importance is 6, and the competitive level for Air Macau is just 2; and for "More flight frequency", Air Macau got the score of 5 in importance, and 2 in competitive level. Such two customer requirements should be paid more attention to.

Target values are set on a 5-point scale (where 1 is no change, 3 is improve the service, and 5 is make the service better than the competition). The sales point is established on a scale of 1 or 2 , with 2 meaning high-sales effect and 1 being low effect on sales. The absolute weight is then found by multiplying the three factors. This is expressed in the following equation:

\section{Absolute Weight $=$ Customer Importance $\times$ Target Value $\times$ Sales Point}

Based on the output of the House of Quality, the "High punctuality" got the highest absollute weight. The second high is "Stable and comfortable" and "Low fault rate" won the third place.

7. Prioritize technical requirements. As shown in Figure3-2, technical requirements are prioritized by determining degree of difficulty, target value, absolute weight, and relative weight. The difficulty is always assigned by design engineers. They determine the degree by technical testing and consulting the literature. Since this part of assessment needs professional knowledge about airplane, we could just get relatively objective evaluation by browsing some news and Internet information. Note that our goal was to get the idea of aspect of service improvement, not to discuss the specific fulfilling steps. So the degree of difficulty would not affect our researching of finding the prioritized technical requirement. The target value for the technical requirements is defined the same way the target values for the customer requirement were assigned.

The values for absolute and relative weights are now established. The method we integrate as follows: Customer

Absolute Weight $=\sum$ Relationship between Customer and Technical Requirements $\times$ Importance to the

Relative Weight $=\sum$ Relationship between Customer and Technical Requirements $\times$ Customer Requirements Absolute Weight

The figure 3 shown follow is the output of "House of Quality":

Source: Service Management, Sixth edition, James A. Fitzsimmons, Mona J. Fitzsimmons, Chapter 6 Service Quality, House of Quality, PP117 


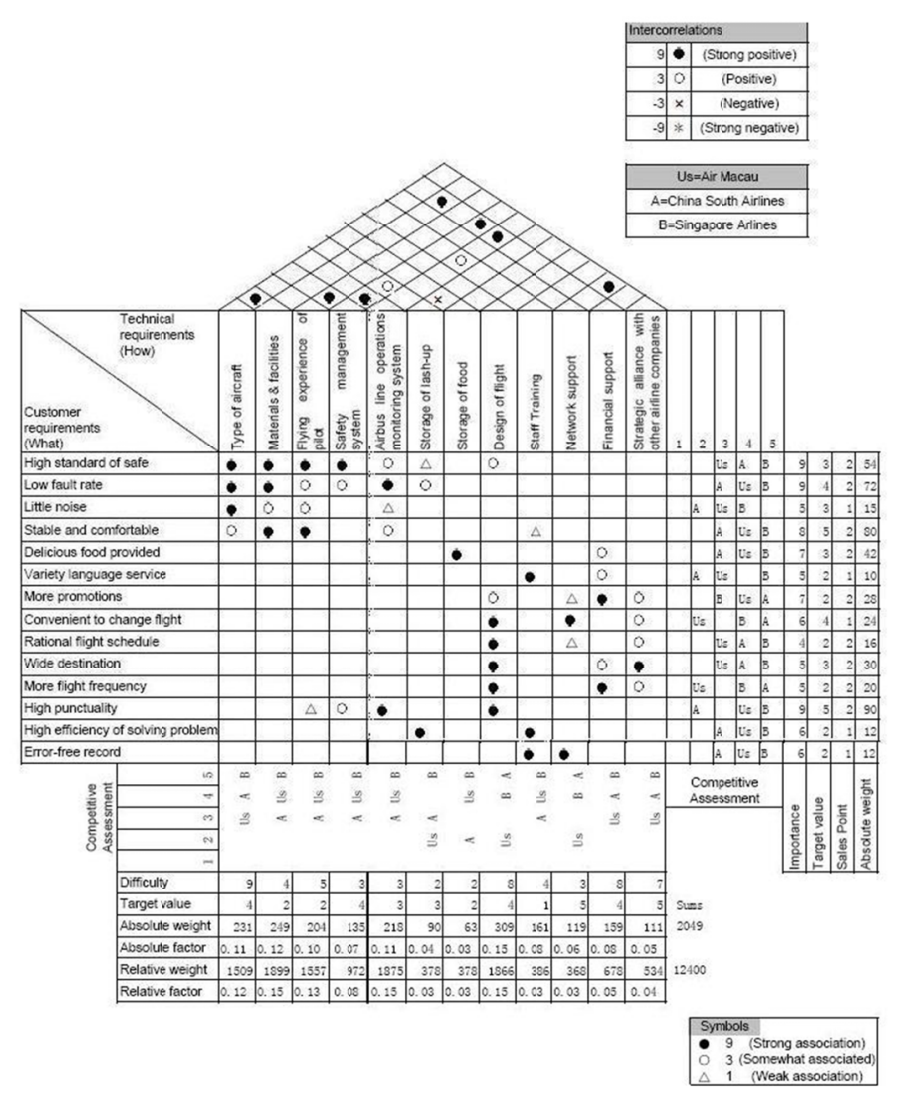

Figure 4. The analytical output of House of Quality

8. Final evaluation. The relative and absolute weights for technical requirements are evaluated to determine what engineering decisions need to be made to improve the design based on customer input. This is performed by computing a percentage weight factor for each of the absolute weight and relative weight factors.

As can be seen in our case, the "Design of flight" got the highest absolute weight (15\%). For relative weight, all of "Design of flight", "Airbus line operations monitoring system" and "Materials and facilities" got the highest rate.

So our conclusion here is that Air Macau may focus on developing the three technical requirements which are "Design of flight", "Airbus line operations monitoring system" and "Materials and facilities".

3.3 Sensitivity Analysis of Robustness of QFD

Because QFD model has the robustness characteristic, here we want to reveal this characteristic by doing a sensitivity analysis, and at the same time, to prove that our conclusion is correct.

We rate from 9 to 1 to show the relationship between customer requirements and technique requirements in our QFD model. Here we change the importance rating while remain other the same, and we look at the output again. First, we use 7 instead to show strong associated, 3 to represent somewhat associated and 1 to stand for weak associated. After using this new rating scale, let's see the output as below: 
Rating $=(7,3,1)$

\begin{tabular}{lllllllllllll}
\hline Difficulty & 9 & 4 & 5 & 3 & 3 & 2 & 2 & 8 & 4 & 3 & 8 & 7 \\
\hline Target value & 4 & 2 & 2 & 4 & 3 & 3 & 2 & 4 & 1 & 5 & 4 & 5 \\
Absolute weight & 185 & 197 & 170 & 117 & 182 & 78 & 49 & 251 & 127 & 95 & 135 & 101 \\
Absolute factor & 0.11 & 0.12 & 0.10 & 0.07 & 0.11 & 0.05 & 0.03 & 0.15 & 0.08 & 0.06 & 0.08 & 0.06 \\
Relative weight & 1227 & 1487 & 1289 & 864 & 1551 & 354 & 294 & 1506 & 318 & 296 & 582 & 474 \\
Relative factor & 0.12 & 0.15 & 0.13 & 0.08 & 0.15 & 0.03 & 0.03 & 0.15 & 0.03 & 0.03 & 0.06 & 0.05 \\
\hline
\end{tabular}

Let's review our original output using rating $(9,3,1)$ :

\begin{tabular}{lllllllllllll}
\hline Difficulty & 9 & 4 & 5 & 3 & 3 & 2 & 2 & 8 & 4 & 3 & 8 & 7 \\
\hline Target value & 4 & 2 & 2 & 4 & 3 & 3 & 2 & 4 & 1 & 5 & 4 & 5 \\
Absolute weight & 231 & 249 & 204 & 135 & 218 & 90 & 63 & 309 & 161 & 119 & 159 & 111 \\
Absolute factor & 0.11 & 0.12 & 0.10 & 0.07 & 0.11 & 0.04 & 0.03 & 0.15 & 0.08 & 0.06 & 0.08 & 0.05 \\
Relative weight & 1509 & 1899 & 1557 & 972 & 1875 & 378 & 378 & 1866 & 386 & 368 & 678 & 534 \\
Relative factor & 0.12 & 0.15 & 0.13 & 0.08 & 0.15 & 0.03 & 0.03 & 0.15 & 0.03 & 0.03 & 0.05 & 0.04 \\
\hline
\end{tabular}

Comparing the two outputs, we find that although we change the rating scale and the absolute values change, the relative values remain the same. The highest three items are still "Materials and facilities", "Airbus line operations monitoring system" and "Design of flight".

We change the importance rating once more, and decide to see whether the result changes as we anticipate. This time, we change the rating scale from $(9,3,1)$ to $(9,3,0)$. Again let's see the output as below:

\begin{tabular}{lllllllllllll}
\hline Difficulty & 9 & 4 & 5 & 3 & 3 & 2 & 2 & 8 & 4 & 3 & 8 & 7 \\
\hline Target value & 4 & 2 & 2 & 4 & 3 & 3 & 2 & 4 & 1 & 5 & 4 & 5 \\
Absolute weight & 231 & 249 & 195 & 135 & 213 & 81 & 63 & 309 & 153 & 108 & 159 & 111 \\
Absolute factor & 0.12 & 0.12 & 0.10 & 0.07 & 0.11 & 0.04 & 0.03 & 0.15 & 0.08 & 0.05 & 0.08 & 0.06 \\
Relative weight & 1509 & 1899 & 1467 & 972 & 1860 & 324 & 378 & 1866 & 306 & 324 & 678 & 534 \\
Relative factor & 0.12 & 0.16 & 0.12 & 0.08 & 0.15 & 0.03 & 0.03 & 0.15 & 0.03 & 0.03 & 0.06 & 0.04 \\
\hline
\end{tabular}

This time, as we earlier anticipated, the result remains the same, and the three items are still those. We can conclude that our model is meaningful and robust, because the sensitivity analysis proves that the results remain the same no matter how we change the rating scale.

\subsection{Limitations on our QFD Model}

Last but not the least; we have to mention the limitations on our QFD model. In the process of constructing our Quality House of QFD model, one of the items named "degree of difficulty" of technique requirements, and its rating scale ranges from 1 to 10 , which means that 1 is the least difficult and 10 the most difficult. The rating requires professional technique engineers to subjectively mark the score according to their related experiences. Although we group-discussed for several times, checked the related websites and reference books, and discussed with our academic advisor about our results, we are neither professionals nor related-specialty student. It is inevitable that our final results may not be exactly correct, due to our lack of practical experiences and expertise knowledge. Moreover, we mainly focus on the orientation of the improvement instead of further concreted measures. Because of our lack in the related knowledge, we also do not further discuss the feasibility of our improvement advices. So, briefly speaking these three drawbacks are the limitation on our QFD model.

\section{Conclusion and Future Considerations}

Tourism and gambling is the leading economic body of Macau SAR, so that the direct economic activities such as aviation, airport operation, and catering on the airplanes, as well as the related indirect economic units such as travel agency, hotel, restaurant, and logistics are closely linked to people from all walks of life. As a result, whether Macau aviation can develop healthily imposes great importance on Macau economy. 
Air Macau is the regional international airline company which is regarded Macau as its base. With the fast pace of financial development in Macau, Air Macau faces great opportunities to develop itself, however, meanwhile the economic crisis and the increasingly high oil price strikes the company. For the future development of Air Macau, opportunities go along with challenges.

For aviation, a special service industry, service quality management is vital to its service management. According to our analysis above, "tangibility" of Air Macau is satisfying to its customers; more concretely, Air Macau can offer satisfying modern tangible facility on its planes. In other words, tangibility can be regarded as Air Macau's strength.

In the contrary, reliability is the shortest board of Air Macau, which means that customers think that the company can't provide its service as it promised. In our questionnaire, the corresponding question is "When you have problems, Air Macau is sympathetic and reassuring" which gets the lowest score. Besides, "Air Macau provides its service at the time it promises to do so", "When Air Macau promises to do something by a certain time, and it does so", "Air Macau is dependable" and "Air Macau keeps its records accurately" also get low score. Actually, many customers regard reliability as the most important item of the five dimensions. So, how to provide the reliable services is the next target of service improvement for Air Macau.

According to the above results, we discover the shortcomings of Air Macau and now we provide several possible suggestions on improvement.

Reviewed our QFD analysis result, we find that punctuality of airline is the customers' focus, which is also the item that enjoys the highest score of customer requirement. It is logical that any delay or cancellation of airline would affect customers' travelling plan and the following plans. To solve this problem, we come up with some feasible suggestions as follows:

First of all, sufficient hardware ensuring work is needed. For example, necessary hardware checking before taking-off and before landing, advanced equipment during flying, and advanced navigation or communication facility.

Besides, reschedule on the fight courses and the number of fights. Unreasonable fight courses and redundant fights cause the problem of supply accesses demand, which then cause financial loss and customers' expectation to decrease.

A quick-respond remedy is needed if the fight delays or is cancelled. Aviation company needs to promptly report the latest news to customers in the waiting room, how long the fight will be delayed, and explain the reasons to the customers. Furthermore, there is a rich literature from the fields of quality control and continuous improvement that will enable greater success for Asian and other aliens to improve service This literature is exemplified in the areas of industrial experimentation, health policy and technology, machine learning, AI and similar fields with the scope of management science/operations research and quality technology. Such applications from problems in similar fields may permit future improvements in quality of service not heretofore practiced. (See; Pan \& Jarrett, 2008; Jarrett \& Pan, 2009; Pan, 2005a; Pan, 2005b; etc.)

The limitations of the combined methods shown in this paper is that although SERVQUAL can help more accurately identify the customer requirements inputs in QFD, however, the way to improve later steps of QFD methods with SERVQUAL to make deeper combination of these two methods still leaves as issues for future studies.

\section{References}

Agus, A., Barker, S., \& Kandampully, J. (2007). An Exploratory Study of Service Quality in the Malaysian Public Service Sector. International Journal of Quality \& Reliability Management, 24(2), 177-190. https://doi.org/10.1108/02656710710722284

Aneesh, M. R., Dileeplal, J., \& Abraham, M. A. (2014). An integrated fuzzy weighted SERVQUAL-QFD approach for service quality improvement. International Journal of Engineering Research, 3(2), 774-776. https://doi.org/10.17950/ijer/v3s12/1215

Bahill, A. T. (1993). Chapman, A tutorial on quality function deployment. Engineering Management Journal, 5(3), 24-35. https://doi.org/10.1080/10429247.1993.11414742

Baki, B., Basfirinci, C. S., \& Cilingir, Z. (2009). An application of integrating SERVQUAL and Kano's model into QFD for logistics services: A case study from Turkey. Asia Pacific Journal of Marketing and Logistics, 2l(1), 106-126. https://doi.org/10.1108/13555850910926272

Baki, B., Basfirinci, C. S., AR, I. M., \& Cilingir, Z. (2009). An application of integrating SERVQUAL and 
Kano's model into QFD for logistics services: A case study from Turkey. Asia Pacific Journal of Marketing and Logistics, 21(1), 106-126. https://doi.org/10.1108/13555850910926272

Baron, R., \& Kenny, D. (1986). The Moderator-Mediator Variable Distinction in Social Psychological Research: Conceptual, Strategic and Statistical Considerations. Journal of Personality and Social Psychology, 51(6), 1173-1182. https://doi.org/10.1037//0022-3514.51.6.1173

Bitner, M. (1990). Evaluating Service Encounters the Effects of Physical Surroundings and Employee Responses. Journal of Marketing, 52(2), 69-82. https://doi.org/10.2307/1251871

Bloemer, J., \& Kasper, H. (1995). The Complex Relationship between Consumer Satisfaction and Brand Loyalty. Journal of Economic Psychology, 16(2), 311-329. https://doi.org/10.1016/0167-4870(95)00007-b

Bossert, J. L. (nd.). Quality Function Deployment: A practitioner's approach, Center for Quality and Applied Statistics. Rochester Institute of Technology

Caruana, A. (202). Service Loyalty: The Effects of Service Quality and the Mediating Role of Customer Satisfaction. European Journal of Marketing, 36(7), 811-828. https://doi.org/10.1108/03090560210430818

Chu-Hua, K., \& Min, H. L. (1997). An integrated approach to service quality improvement. International Journal of Quality Science, 2(1), 24-36.

Diaz, A., \& Ruiz, F. (2002). The Consumer's Reaction to Delays in Service. International Journal of Service Industry Management, 13(2), 118-140. https://doi.org/10.1108/09564230210425331

Ennew, C., \& Binks, M. (1996). The Impact of Service Quality and Service Characteristics on Customer Retention: Small Businesses and Banks in the UK. British Journal of Management, 7(3), 219-230. https://doi.org/10.1111/j.1467-8551.1996.tb00116.x

Glaveli, N., Petridou, E., Liassides, C., \& Spathis, C. (2006). Bank Service Quality: Evidence from Five Balkan Countries. Managing Service Quality, 16(4), 380-394. https://doi.org/10.1108/09604520610675711

Gronroos, C. (1984). A service Quality Model and Its Marketing Implications. European Journal of Marketing, 18(4), 36-44. https://doi.org/10.1108/eum0000000004784

Hair, J., Black, W., Babin, B., Anderson, R., \& Tatham, R. (2006). Multivariate Data Analysis (6th ed.), Pearson Education, Inc., Upper Saddle River.

He, Y., \& Song, H. (2009). A Mediation Model of Tourists' Repurchase Intentions for Packaged Tour Services. Journal of Travel Research, 47(3), 317-331. https://doi.org/10.1177/0047287508321206

Horstmann, R. (1998). Customer Satisfaction and Loyalty: An Empirical Assessment in the Service Industry. Journal of Applied Management and Entrepreneurship, 4(3), 39-54.

Hu, J. S., \& Feng, T. (nd). Statistics for Practice (1st ed.). Peking University Press.

Jarrett, J., \& Pan, X. (2009). Multivariate process control chart and their use in monitoring output quality: A perspective. International Journal of Industrial and Systems Engineering, 4(5), 471-482. https://doi.org/10.1504/ijise.2009.024154

Johnston, R. (1995). The Determinants of Service Quality: Satisfiers and Dissatisfies. International Journal of Service Industry Management, 6(5), 53-71.

Kotler, P., Ang, S., Leong, S., \& Tan, C. (1999). Marketing Management: An Asian Perspective. Prentice Hall Inc., Upper Saddle River.

Lee, M., \& Cunningham, L. (2001). A Cost/Benefit Approach to Understanding Service Loyalty. Journal of Services Marketing, 15(2), 113-130. https://doi.org/10.1108/08876040110387917

Lehtinen, U., \& Lehtinen, J. (1982). Service Quality—A Study of Dimensions. Service Management Institute, Helsinki.

Lewis, C., \& Booms, B. (1983). The Marketing Aspects of Service Quality. In Berry, L. L., Shostack, G. and Upah, G., (Eds.), Emerging Perspectives in Service Marketing. American Marketing Association, Chicago. https://doi.org/10.1177/009207038501300332

McAlexander, J., Kaldenberg, D., \& Koenig, H. (1994). Service Quality Measurement. Marketing Health Services, 14(3), 34-40.

Mohsan, F. (2011). Impact of Customer Satisfaction on Customer Loyalty and Intentions to Switch: Evidence from Banking Sector of Pakistan. International Journal of Academic Research in Business and Social 
Sciences, 2(16).

Mouawad, M., \& Kleiner, B. (1996). New Developments in Customer Service Training. Managing Service Quality, 6(2), 49-56. https://doi.org/10.1108/09604529610109774

Nguyen, N., \& Leblanc, G. (2001). Corporate Image and Corporate Reputation in Customers' Retention Decisions in Services. Journal of Retailing and Consumer Services, 8(4), 227-236. https://doi.org/10.1016/s0969-6989(00)00029-1

Nunnally, J., \& Bernstein, I. (1994). Psychometric Theory. New York: McGraw-Hill, Inc.

Pan, X. (2005). An Alternative Approach to Multivariate EWMA Chart. Journal of Applied Statistics, 32(7), 695-705.

Pan, X. (2005). Notes on Shift Effects of T2-type Charts for Residuals of Multivariate ARMA Processes. Computers \& Industrial Engineering, 49(3), 318-352. https://doi.org/10.1016/j.cie.2005.07.001

Pan, X. (2006). Computer-Aided SPC: The Cybernetic View on Quality Control. International Journal of Quality and Reliability Management, 23(9), 1192-1203. https://doi.org/10.1108/02656710610704276

Pan, X., \& Jarrett, J. E. (2008). Estimating $\sigma$ and Improving Control Limits with RWAV for Normal and Nonnormal Processes. Quality Engineering, 21, 72-78. https://doi.org/10.1080/08982110802450769

Paswan, A., Spears, N., Hasty, R., \& Ganesh, G. (2004). Search Quality in the Financial Services Industry: A Contingency Perspective. Journal of Services Marketing, 18(5), 324-338. https://doi.org/10.1108/08876040410548267

Sangeeta, S., Banwet, D. K., \& Karunes, S. (2004). A SERVQUAL and QFD approach to total quality education: A student perspective. International Journal of Productivity and Performance Management, 53(2), 143-166. https://doi.org/10.1108/17410400410515043

Seth, N., Deshmukh, S., \& Vrat, P. (2005). Service Quality Models: A Review. International Journal of Quality \& Reliability Management, 22(9), 913-949. https://doi.org/10.1108/02656710510625211

Sui, P. L., \& Rui, Z. (2016). SERVQUAL, the Kano Model and QFD. In Service Quality for Facilities Management in Hospitals. Springer, Singapore. https://doi.org/10.1007/978-981-10-0956-3_3

Sureshchandar, G., Rajendran, C., \& Anantharaman, R. (2002). Determinants of Customer-Perceived Service Quality: A Confirmatory Factor Analysis Approach. Journal of Services Marketing, 16(1), 9-34. https://doi.org/10.1108/08876040210419398

Tee, L. (2012). The Effects of Service Quality, Customer Satisfaction on Re-Patronage Intentions of Hotel Existing Customers. International Journal of Management and Administrative Sciences, 1(8), 60-73.

Zairi, M. (2000). Managing Customer Dissatisfaction through Effective Complaint Management Systems. The TQM Magazine, 12(5), 331-335. https://doi.org/10.1108/09544780010341932

Zeithaml, V., Berry, L., \& Parasuraman, A. (1996). The Behavioral Consequences of Service Quality. Journal of Marketing, 60(2), 31-46. https://doi.org/10.2307/1251929

\section{Copyrights}

Copyright for this article is retained by the author(s), with first publication rights granted to the journal.

This is an open-access article distributed under the terms and conditions of the Creative Commons Attribution license (http://creativecommons.org/licenses/by/4.0/). 